Peer-Reviewed Article

ISSN: 2162-3104 Print/ ISSN: 2166-3750 Online

Volume 7, Issue 3 (2017), pp. 703-727

(C) Journal of International Students

http://jistudents.org/

doi: 10.5281/zenodo.570029

\title{
A Developmental Sequence Model to University Adjustment of International Undergraduate Students
}

\author{
Saeid Chavoshi \\ Maxine Gallander Wintre \\ Stella Dentakos \\ Lorna Wright \\ York University, Canada
}

\begin{abstract}
The current study proposes a Developmental Sequence Model to University Adjustment and uses a multifaceted measure, including academic, social and psychological adjustment, to examine factors predictive of undergraduate international student adjustment. A hierarchic regression model is carried out on the Student Adaptation to College Questionnaire to examine theoretically pertinent predictors arranged in a developmental sequence in determining adjustment outcomes. This model accounted for over $60 \%$ of the variance in adjustment scores, and highlighted the importance of ecological factors in relation to student adjustment, such as social support, relationship with parents, and perceived institutional support as more useful than static measures of achievement such as high school GPA. Implications of these findings, including the important role of campus services, are discussed.
\end{abstract}

Keywords: adjustment to university, developmental sequence model, emerging adulthood, undergraduate international students

The presence of international students in our institutions provides a host of political, financial and social benefits. These students act as agents of internationalization, adding to the diversity of the student population, providing a more globalized perspective, enhancing the exchange of ideas within the university, and broadening cultural understanding in and out of the classroom (Bevis 2002; Institute of International Education, 2012). The presence of international students also helps develop and maintain 
relationships that will create trading partnerships with emerging markets (Zhou \& Scratchley, 2005).

Aware of these cultural and economic benefits, universities and governments are presently increasing their efforts to attract international students (Verbik \& Lasanowski, 2007). In the United States, the percentage of international students has increased by $32 \%$ over the last decade, constituting $3.7 \%$ of the student body, or 20.6 million students in the 2011/12 academic year (Institute of International Education, 2012). In Canada, international student enrolment rates have grown 94\% since 2001, constituting approximately $12 \%$ of total university students in 2010 (CBIE, 2013; Foreign Affairs, Trade and Development Canada, 2013). However, despite government initiatives on increasing international enrolment, there has been limited empirical research on the experiences of international students and their transition and adjustment to university (Lee, 2010; Zhang, \& Goodson, 2011).

\section{LITERATURE REVIEW}

In order for universities to provide the best environment for international students, it is important to understand the unique challenges that international students face academically and psychologically during their adjustment and the transition to university. Existing research suggests that international students tend to experience a magnification of common student problems such as difficulty with academic work, social isolation, and support needs (Gebhard, 2012; Ramsay, Jones \& Barker, 2006). Plus they may experience specific problems such as culture shock, language difficulties, and adjustment to unfamiliar social norms, eating habits and customs, as well as homesickness and a loss of established social networks (Church, 1982; Mesidor \& Sly, 2016; Zhang, \& Goodson, 2011). The present research advances the research in the area by being more comprehensive regarding potential predictor variables as informed by theoretical considerations from developmental systems theory (Lerner, 2004) and emerging adulthood (Arnett, 2000) adapted for international students. It also addresses the concern that previous lines of research in the field are hindered by inconsistency in operationalization and measurement of adjustment (Al-Sharideh \& Goe, 1998; Searle, 1990; Zhang, \& Goodson, 2011).

\section{Theoretical Considerations}

The developmental systems perspective (Lerner, 2004) posits that human development is a dynamic and relational phenomenon, shaped by reciprocally acting and mutually influential factors related to persons, place, and time. Individual and context constitute an intertwined system that 
continues to develop over the lifespan. The developmental systems framework guides researchers interested in understanding and promoting positive human development by suggesting a number of factors to consider (Lerner, 2004). First, it is important to identify attributes of the individual that contribute to positive and negative development. In the case of international students, demographic factors such as country of origin have been associated with adaptation outcomes (Hechanova-Alampay et al., 2002; Mori, 2000).

The second factor Lerner (2004) suggests is the influence of relationships on individual development. Our lives are embedded in social relationships, which themselves undergo transitions. International students are faced with a profound change in their social relations, and their social support during their sojourn has been implicated in a number of positive adjustment outcomes (Ramsay et al., 2007). Mallinckrodt and Leong (1992) studied eight factors of social support among international students and found most of them directly related to depression, anxiety, and physical health symptoms. Furthermore, the quality of the social support system also had a buffering effect when international students were undergoing psychological stress (Lee, Koeske \& Sales, 2004). Within the context of emerging adulthood, the Social Relations Theory (Youniss \& Smollar, 1985 ) indicates that as late adolescents begin to strive toward autonomy and self-sufficiency, their relationships with their parents become less dependent, and more mutually respectful, and reciprocal. This developing reciprocity has been found to impact well-being in emerging adults, particularly in domestic students' adjustment to university (e.g., Wintre, Yaffe, \& Crowley, 1995; Wintre \& Yaffe, 2000; Wintre \& Bowers, 2007).

Emerging adulthood is a developmental period distinct from adolescence and adulthood and typically represents development from the ages of 18 to 29 (Arnett, 2006; 2012). Arising out of relatively recent societal changes in the Western industrial world, Arnett's (2000) Emerging Adulthood Theory posits that adolescence has been extended as a result of the societal need for more education and training. As a result, emerging adults typically postpone serious committed life roles, such as marriage. This lack of permanent roles results in increased mobility and a greater number of available life choices for today's young adults, allowing for the exploration of possible life directions (Arnett, 2000). This adventure often involves both physical and psychological dimensions, for example involving moving away from home, attempting different academic subjects, trying out various career paths, and exploring identities (Arnett, 2000; 2006; 2012). A recent qualitative study examining the decision-making processes and motivations of international students to study abroad noted that while not from Western industrialized countries, international students meet the definition of emerging adults as evidenced by sharing the five hallmark 
features of emerging adulthood, namely, identity exploration, self-focus, instability, optimism, and feeling in between (Wintre, Kandasamy, Chavoshi, \& Wright, 2015).

Lerner also emphasizes the broader ecological conditions which can affect development. Emerging adulthood often involves changing environments, such as moving out of the parental home or to a new school, experiences that are particularly salient to international students (Arnett, 2000). According to the person-environment fit (PEF) theory (Eccles, Lord, \& Roeser, 1996), some of the negative outcomes experienced during transitions to university are a result of a mismatch between the needs of the developing individual and the opportunities provided by the social and academic environment. A mismatch between the university environment and the psychological and developmental needs of the students is posited to result in a decline in motivation, interest and performance of the students (Eccles et al., 1996).

Informed by PEF theory and Lerner's developmental systems perspective, two process oriented measures, Student University Match (SUM; Wintre, Knoll, Pancer, Pratt, Polivy, Birnie-Lefcovitch et al., 2008) and Student Perception of University Support and Structure (SPUSS; Wintre, Gates, Pancer, Pratt, Polivy, Birnie-Lefcovitch, \& Adams, 2009), were developed and validated with Canadian domestic undergraduate students. These measures focus on the dynamic and ongoing interaction between the student and university, rather than static traits of the individual. They also tap into variables that do not exist prior to attending the university and involve the individuals' reflections on their chosen university as a result of their interactions experienced at the institution. Canadian studies with students attending six different Canadian universities presented evidence that these "process" measures are predictive of domestic student adjustment, and capable of distinguishing between "persisters" and "desisters" (Wintre et al, 2008, Wintre et al, 2009). Therefore, the relation between international students' perception of university fit and their interaction with the institution will be included in the current study.

In line with a developmental systems perspective, Wintre and Yaffe (2000) proposed a model that examined factors determining student adjustment at university in a developmental sequence. They theorized that the pre-entry characteristics and learning history of the students (e.g., gender, immigrant-generational status, socioeconomic status and parental education level, relations with parents, high school GPA, etc.) influence participation in the academic and social systems of the university, thereby helping to shape their university adjustment. Wintre and Bowers (2007) validated this developmental sequence approach to studying domestic students' perseverance and found the model could predict degree completion. In the case of international students, it is postulated that these 
factors should be extended to include English competence and social support during students' sojourn (Rawlings \& Sue, 2013).

\section{Defining the Adjustment of International Students}

Researchers have defined adjustment in various ways, including specific problems such as academic issues, time management, adaptation to the local diet, or financial issues (Johnson, 1971; Stafford, Marison \& Salter, 1980; Taft, 1977; Vaz, 1984); while others examine constructs such as achieving high self-esteem, satisfaction with life, physical and mental health symptomology, mood states, coping with everyday activities, feelings of acceptance, and social interaction with host nationals (Al-Sharideh \& Goe, 1998; Chirkov, Safdar, de Guzman \& Playford, 2008; Chirkov, Vansteenkiste, Tao \& Lynch, 2007; Matsumoto, LeRoux, Bernhard \& Gray, 2004; Downing-Burnette, Heller, Binder \& Suntinger, 2004; Feinstein \& Ward, 1990; Savick, Van Oudenhoven \& Van der Zee, 2002). Finally, some researchers create custom adjustment scales based on their own intuitions (Gong \& Fan, 2006; Ramsay et al., 2006). This ambiguous and variegated use of the term "adjustment" complicates the interpretation and comparisons of findings, making their integration into the literature difficult.

After reviewing more than three decades of research, Church (1982) was critical of the issue-centric nature of most investigations and a lack of a tenable theoretical framework to guide and encourage new research hypotheses. One of the earliest frameworks proposed to describe the adjustment of sojourners, is the U-curve model of adjustment (Gullahorn \& Gullahorn, 1963; Lysgaard, 1955). This model posits a sojourner's level of adjustment as a function of the time spent in the host country. The adjustment of the international student is depicted by the theory of undergoing an initial "honeymoon period" characterized by optimism and elation in the host culture fueled by the new experience, followed by a dip or depressive period, then a recovery period leading to better adjustment (see Black \& Mendenhall, 1990; Thomas \& Harrell, 1994). However, the validity and usefulness of this theory has been extensively criticized. Some criticisms include: 1) that the U-curve theory does not provide information with regard to the mechanisms of adjustments or why each of the different stages of adjustment starts and ends; 2) the theory is over generalized to explain diverse experiences of different types of sojourners (students, immigrants etc.); 3) not all international students experience the honeymoon, depression, and recovery stages and; 4) the theory resembles a post hoc description of adjustment data rather than an explanation of the adjustment process (Church, 1982; Thomas \& Harrell, 1994; Toyokawa \& Toyokawa, 2002).

Researchers have attempted to address these shortcomings by extending various theoretical frameworks to international student research. 
For example, Chirkov and colleagues $(2007 ; 2008)$ used Self Determination Theory (SDT) to hypothesize that self-driven motivation to study abroad would benefit students' adaptation. SDT posits that any behavior can differ in its degree of experienced self-determination. In other words, people can engage in an activity because of self-driven motivation and a feeling of ownership of their behavior or they can feel pressured to partake in the activity (Deci \& Ryan, 1985). Chirkov and colleagues (2007; 2008) designed a scale to measure the self-determined motivation in international students' choice to study abroad. This measure was first tested on a crosssectional sample of Chinese international students studying in Belgium and Canada (Chirkov et al., 2007), and later in a longitudinal study of international students at three Canadian institutions (Chirkov et al., 2008). They demonstrated that self-determination in choosing to study abroad is associated with positive psychological well-being (i.e., satisfaction with life, etc.) and higher GPA.

Chirkov et al. $(2007 ; 2008)$ had also examined the motivation to acculturate to the host culture as a predictor of adaptive psychological and social outcomes for international students, showing that international students' level of acculturation motivation was positively related to psychological health and negatively related to both psychosomatic and social difficulties (Chirkov, 2008). More recently, these findings were validated and extended using a mixed methods approach, with both qualitative and quantitative findings showing that motivation to acculturate is associated with more positive descriptions of the host country experience, with better international student adjustment, and with increased intentions of pursuing permanent host country residency (Dentakos, Wintre, Chavoshi, \& Wright, 2016).

The importance of self-driven motivation to study abroad on students' adaptation (Chirkov et al. 2007; 2008) may be complemented by using adjustment scales with established validity for use with postsecondary students (e.g. the Student Adaptation to College Questionnaire, SACQ: Baker \& Siryk, 1989), and a theoretical framework that considers students' developmental history and current developmental stage, including their roles as students. The present study incorporates these previous findings within a developmental theoretical framework to create and examine a comprehensive model of international student adjustment that is informed by a developmental systems framework and by the students' developmental stage as emerging adults.

\section{Measuring Student Adjustment}

Baker and Siryk (1984) posit that student adjustment to college is multifaceted. Similarly, Lee (2010) argues that focusing only on academic achievement or retention fails to capture the experiences of students who 
persist through unusual resolve or due to cultural pressures despite facing distress and psychosocial problems. For example, Wang (2000) pointed out that Chinese students in the USA tend to persevere because of their strong determination and cultural values about 'saving face'. Such untoward experiences, aside from adversely affecting the psychological well-being of these students, can also diminish enrolments given the role word of mouth recommendation plays in this market (Lee, 2008; Pimpa, 2003).

A multifaceted approach to measuring adjustment examines multiple domains of consequence and has been advocated by researchers (Tinto, 1996; Wintre \& Bowers, 2007). Possible domains include student's self-reports of psychological well-being, involvement in campus activities, quality of social life, academic standing, and attachment to their university. Baker and Siryk (1999) developed the Student Adaptation to College Questionnaire (SACQ) based on such a multifaceted view of student adjustment The SACQ yields a total score, as well as four subscales measuring academic adjustment, social adjustment, personal-emotional adjustment, and institutional commitment.

The SACQ, with demonstrated strong reliability and psychometric properties, has been widely used in research of student transition to university (e.g., Baker et al., 1985; Baker \& Siryk, 1984, 1989, 1999; Beyers \& Goossens, 2003; Buote et al., 2007; Cooper \& Robinson, 1988; Krotseng,1992; Mooney, Sherman, \& LoPresto, 1991; Wintre \& Morgan, 2009). Furthermore, a number of studies lend credence to the criterion and predictive validity of the SACQ (e.g. Conti, 2000; Gerdes \& Mallinckrodt, 1994; Hertel, 2002; Mooney et al., 1991; Schwitzer, Robbins, \& McGovern, 1993; Wintre \& Bowers, 2007; Wintre \& Yaffe, 2000). The SACQ has also been effectively used with different racial, ethnic and national groups (e.g., Beyers \& Goossens, 2002; Gold et al., 1990; Hinderlie \& Kenny, 2002; Hurtado, Carter \& Spuler, 1996; Norvilitis, Sun \& Zhang, 2010; Tao, Dong, Pratt, Hunsberger \& Pancer, 2000). Given the SACQ's demonstrated effectiveness for research on diverse undergraduate populations, it is timely that the SACQ be used by researchers examining the adjustment of undergraduate international students.

\section{RESEARCH METHOD}

Informed by the developmental-systems approach (Lerner, 2004), the present study aimed to identify attributes of international students that are associated with positive adjustment. These include personal and demographic attributes (gender, country of origin, age, parents' level of education, socio-economic status, motivation to acculturate), prior demonstration of positive adaptation (high school GPA, self-perceived English Competence), social and relational factors (perceptions of parental 
reciprocity, autonomy in motivation to study abroad, residence status, social support) and institutional interactions (perceptions of university match and support structure). Note that standardized English tests scores, such as TOEFL or IEALT, were not included in the analysis because a previous investigation with the same cohort and other studies have found them to be poor predictors of adjustment and the future GPA of international students (Chavoshi, Wintre, \& Wright, 2012; Fass-Holmes \& Vaughn, 2015). Using a cross-sectional sample of undergraduate international students, a hierarchical regression model with variables pertinent to a developmentalsystems framework, arranged in developmental sequence, is used to examine adjustment outcomes with the total SACQ scores. Students' year of study was controlled.

These variables are arranged in a hierarchical regression in an order that reflects The Developmental Sequence Model to University Adjustment (DSMUA: Wintre and Yaffe, 2000; Wintre \& Bowers, 2007). The arrangement of variables, from distal to proximal in terms of temporal relevance to student development, allows earlier blocks to correspond to distal developmental variables. For example, demographic variables and country of origin are placed in the distal block, whereas variables based on interaction with university are entered in the last block, as they represent the most proximal developmental variables in the model measuring the effects of an ongoing and dynamic interaction between the student and the institution. Proximal factors whose influence began prior before the international student's sojourn, such as the autonomy in their motivation to study abroad, the perception of reciprocity in their changing parental relations, and their motivation to acculturate, were entered in the Transitional (middle) block (See Table 3).

Hierarchical regression examines the influence of several predictor variables in a sequential way, such that the relative importance of a predictor may be judged on the basis of how much it adds to the prediction of a criterion of interest, over and above that which can be accounted for by other pertinent predictors (Cohen, 2001; Wampold \& Freund, 1987). Partial (non-hierarchical) results are also presented to provide information on the unique variance contributed by any predictor variable controlling for all others.

\section{Participants}

Participant data originate from a larger mixed methods investigation (involving both surveys and interviews) of undergraduate international student adjustment. Participants included undergraduate international students with no prior educational experience in Canada, attending a large ethnically diverse, Canadian university (student population greater than 55,000 ) in a multi-cultural metropolitan city (population greater than 2.5 
million). During February 2012, an email was sent to a listserv maintained by the International Student Office, inviting undergraduate international students to participate in a half-hour online survey hosted on Survey Monkey. Students were offered $\$ 10$ for their participation in this survey, regardless of finishing it. A second email was sent out during March 2012, and data collection was wrapped up by end of April 2012. At the end of the data collection 220 students finished the survey. Of those, two were removed from the dataset because of reporting a high school average that was below passing, suggesting a data entry error. Five other participants were removed because they were older than 30 years old; above the age of interest for emerging adulthood. Finally, four participants were missing data on the key measures of interest, and they were removed from the analysis, leaving 209 subjects who were involved in the subsequent analysis, of whom $62 \%$ are females, the mean age is $21.6(S D=2.28), 47 \%$ had lived on campus, $31.6 \%$ are in first year, $29.2 \%$ in second year, $23.9 \%$ in third, and $15.3 \%$ in fourth year and beyond.

\section{Measures}

Demographic Variables. Students reported their age, gender, high school GPA (as a percentage), current academic year, family income (below average income, average income, above average income, well above average income), and father and mothers' level of education (i.e. completed high school, some undergraduate school). Regarding country of origin, given that students identified 60 countries, the authors categorized the countries into geographic areas (e.g. South Asia, Caribbean, China and Hong Kong, East Asia, Africa, Latin America, Middle Eastern and predominantly Arab nations, and Other). Students were also asked about their residence history. If they were currently, or had previously, lived on campus in a university residence they were assigned a value of 1 , otherwise a value of 0 for Residence Status.

English Competence. Proficiency in English was measured by taking the average of three questions that asked the students to rate their proficiency based on a 4-point Likert-type scale in the areas of understanding, speaking, and writing English.

Perception of Parental Reciprocity Scale (POPRS; Wintre et al., 1995). This 43-item measure assesses the degree of perceived reciprocity in emerging adults' relationships with their parents. POPRS contains three subscales: general feelings of mutual reciprocity (e.g., "There is mutual respect between me and my parents even in areas in which we disagree." 9 items), relationship with mother and father (e.g., "I often feel that my father is talking "at" me and not with me"; 16 items for each). Responses are given on a six-point scale ranging from 1 (strongly disagree) to 6 (strongly agree), and higher overall scores reflect heightened feelings of reciprocity. In the present data set the Cronbach alpha was .93. 
Relative Autonomy Index (Derived from the Self-Regulation Questionnaire-Study Abroad: SRQ-SA: Chirkov et al., 2007). Items on the SRQ-SA gauge four types of motivation based on the Self-Determination Theory (SDT). Intrinsic Motivation represents the perception that studying abroad is an exciting, satisfying, interesting, and challenging opportunity. Ten items were rated on a 5-point Likert-type scale, ranging from 1 (not at all because of this reason) to 5 (completely because of this reason). Positive scores represent the prevalence of Autonomous Motivation (Intrinsic Motivation and Identified Regulation combined) over Controlled Motivation (External and Introjected combined), and vice versa in the case of negative scores. Present Cronbach alpha was .71.

The Acculturation Motivation Scale (AMS; Chirkov et al., 2007) assesses international students' willingness to interact with the host country context and consists of 15 items with five-point Likert-type response formats. Examples items are "I am interested in learning more about Canada"; "I try to avoid interactions with Canadians unless it is absolutely necessary". Present study's Cronbach alpha was .87.

Social Provisions Scale (SPS; Cutrona, 1984). The SPS contains 24 items that gauge the degree to which respondents feel their social relationships are supporting them (e.g., "I have close relationships that provide me with a sense of emotional security and well-being"). Responses are indicated on a nine-point scale and range from -4 (not at all true) to +4 (completely true). Elevated scores indicate more social support. Alpha with these international students was .92 .

Student University Match (SUM; Wintre, et al., 2008). This is a 17item scale designed to measure the quality of match between students' individual goals and needs and the opportunities provided by their university, with higher scores indicating a better perceived match. Responses range on a Likert-type scale from 0 to 4 , where 0 represents absolutely no fit, 2 represents neither a good fit nor a bad fit, and 4 represents a great fit. Similar to the alpha (.87) for domestic students, the present alpha is .93 .

Students' Perception of University Support and Structure (SPUSS; Wintre, et al, 2009). This 21-item questionnaire measures the students' perceptions of university support and structure. An example of a support item is "If a student needed help for an emotional problem, it would be easy to find a service on campus to help them". An example of a structure item is "Professors in classes make it clear what students are expected to do in order to get a good grade on assignments, papers and tests". Items were rated on a 9-point rating scale ranging from -4 (very strongly disagree) to +4 (very strongly agree). Higher scores indicated a better perception of university support and structure. In the current study, this scale had a Cronbach alpha of .88 . 
Student Adaptation to College Questionnaire (SACQ; Baker \& Siryk, 1989). This 67-item questionnaire measures college or university adjustment. It has four subscales, including a 24-item Academic Adjustment subscale which measures self-perceptions of coping with the academic demands of the university (e.g. "I am enjoying my academic work at university."); a 20-item Social Adjustment subscale that measures interpersonal adaptation (e.g. "I am meeting as many people, and making as many friends as I would like at university"); a 15-item Personal-Emotional subscale assessing students' psychological and physical wellbeing (e.g. "I am experiencing a lot of difficulty coping with the stresses imposed on me in university"); and a 15-item Institutional-Attachment subscale that measures a student's commitment to the institution they are attending (e.g. "Lately I have been giving a lot of thought to transferring to another university"). Items were rated on a 9-point rating scale ranging from 1 (Doesn't apply to me at all) to 9 (Applies very closely to me), with higher scores on the scale indicating better university adjustment. In the current study, the Cronbach alphas were .93 for total SACQ, .86 for academic subscale, .84 for social subscale, .87 for personal-emotional, and .79 for Institutional Attachment.

\section{RESULTS}

Preliminary analyses including Cook's distance (Cook, 1977) Studentized Deleted Residuals and Leverage values to scan for outliers, and tests for normality and collinearity, revealed no concerning cases or outliers.

Table 1: Descriptive Statistics $(N=209)$

\begin{tabular}{lcccc}
\hline Variables & $M$ & $S D$ & Min & Max \\
\hline Age & 21.62 & 2.28 & 17.00 & 28.00 \\
Academic Year & 2.23 & 1.06 & 1.00 & 4.00 \\
Current GPA & 2.84 & 0.81 & 1.00 & 4.00 \\
English Competence & 12.16 & 2.42 & 6.00 & 15.00 \\
Family Financial Situation & 2.55 & 0.69 & 1.00 & 4.00 \\
High School GPA & 81.97 & 7.80 & 60.00 & 100.00 \\
Father's Education Level & 4.04 & 1.79 & 0.00 & 6.00 \\
Mother' Educational Level & 3.40 & 1.78 & 0.00 & 6.00 \\
Perception of Parental Reciprocity & 4.30 & 0.69 & 2.05 & 5.77 \\
Relative Autonomy Score & 6.55 & 7.42 & -20.00 & 21.00 \\
Acculturation Motivation & 3.87 & 0.61 & 2.27 & 5.00 \\
Social Provisions Scale & 1.68 & 1.26 & -2.86 & 4.00 \\
Student Perception of University Support \& & & & & \\
Structure & 5.60 & 1.00 & 1.80 & 8.25 \\
\hline A total of 209 participants completed all measures used in the hierarchical \\
regression models. Region of Origin was a categorical variable with eight
\end{tabular}


levels (see Table 2), including seven dichotomous dummy variables to contrast regions of origin to China, which was used as the reference (peg) variable.

Table 2: Country of Origin and Region Division $(N=209)$

\begin{tabular}{|c|c|c|c|}
\hline Region & Countries included & Freq. & Percent \\
\hline $\begin{array}{l}\text { China and } \\
\text { Taiwan }\end{array}$ & China, Taiwan & 83 & 39.7 \\
\hline East Asia & $\begin{array}{l}\text { Thailand, Vietnam, Japan, South Korea, Indo- } \\
\text { nesia, Singapore, Republic of Korea, } \\
\text { Philippines, Cambodia, Malaysia }\end{array}$ & 34 & 16.3 \\
\hline South Asia & India, Pakistan, Sri Lanka, Bangladesh & 33 & 15.8 \\
\hline Caribbean & $\begin{array}{l}\text { Jamaica, Cayman Islands, Barbados, St. Lucia, } \\
\text { Trinidad and Tobago, Jamaica, St. Vincent, The } \\
\text { Bahamas }\end{array}$ & 18 & 8.6 \\
\hline Africa & $\begin{array}{l}\text { Kenya, Nigeria, Tanzania, Egypt, Malawi, } \\
\text { Ghana, DR Congo, Ethiopia, Swaziland }\end{array}$ & 15 & 7.2 \\
\hline Middle East & $\begin{array}{l}\text { Syria, Kuwait, Lebanon, Turkey, Yemen, Saudi } \\
\text { Arabia, Iran, UAE, Qatar }\end{array}$ & 8 & 3.8 \\
\hline Latin & $\begin{array}{l}\text { Venezuela, Peru, Chile, Brazil, Mexico, Co- } \\
\text { lombia, Nicaragua, }\end{array}$ & 8 & 3.8 \\
\hline Other & $\begin{array}{l}\text { Israel, Denmark, Azerbaijan, USA, Kazakhstan, } \\
\text { Russia, Croatia, Mauritius. }\end{array}$ & 10 & 4.8 \\
\hline Total & & 209 & 100.0 \\
\hline
\end{tabular}

Table 3 presents the results from the hierarchic regression, the change in $R$ and $F$ as different blocks of predictor variables were entered, and provides the standardized beta $(\beta)$ and the corresponding squared semi-partial correlations $\left(s r^{2}\right.$ - a measure of variance explained in the dependent measure by the predictor while controlling for other variables in the model). The hierarchic regression model on SACQ total scores significantly accounted for $60.1 \%$ (Adjusted $R^{2}$ ) of the variance, $F(22,186)=15.27, p<0.001$. The first block entered, Distal Predictors, contributed significantly to the model, $\Delta R^{2}=.127, p=.011$. Within that block, demographic variables and high school GPA were not significant, but some countries of origin were significant predictors. The relative performance of students from the Caribbean $\left(s r^{2}=.03\right)$, Africa $\left(s r^{2}=.02\right)$, Middle East $\left(s r^{2}=.03\right)$, and Other $\left(s r^{2}=.03\right)$, compared to students from China, were significant positive predictors of SACQ scores, with small effect sizes.

The second block, containing the Transitional Predictors, resulted in a significant change in $R^{2}\left(\Delta R^{2}=.168, p<.001\right)$; it included the significant predictors Perception of Parental Reciprocity (POPRS) and Acculturation Motivation. Higher scores on Perceived Parental Reciprocity predicted better adjustment outcomes, with a medium effect size accounting for $12 \%$ 


\section{Table 3: Hierarchical Regression Analysis on SACQ Scores}

\begin{tabular}{|c|c|c|c|c|c|}
\hline \multirow{2}{*}{ Blocks and predictor variables } & \multirow[b]{2}{*}{$\Delta R^{2}$} & \multirow[b]{2}{*}{$\Delta F$} & \multicolumn{3}{|c|}{ Hierarchical Results } \\
\hline & & & $\beta$ & $s r^{2}$ & $p$ \\
\hline Control: Academic Year & .009 & 1.97 & .097 & 0.01 & .162 \\
\hline Distal Predictors & .127 & 2.19 & & & .011 \\
\hline Gender $(1=\mathrm{M}, 2=\mathrm{F})$ & & & .028 & 0.00 & .705 \\
\hline Age & & & .078 & 0.00 & .332 \\
\hline Family Income & & & .104 & 0.01 & .156 \\
\hline Mother's Education & & & -.024 & 0.00 & .771 \\
\hline Father's Education & & & .029 & 0.00 & .733 \\
\hline China (Reference Peg) & & & & & \\
\hline Caribbean & & & .170 & 0.03 & .027 \\
\hline South Asia & & & .118 & 0.01 & .125 \\
\hline East Asia & & & -.035 & 0.00 & .645 \\
\hline Africa & & & .161 & 0.02 & .028 \\
\hline Mid-East & & & -.163 & 0.03 & .024 \\
\hline Latin America & & & .031 & 0.00 & .662 \\
\hline Other & & & .159 & 0.03 & .025 \\
\hline High school GPA & & & .013 & 0.00 & .861 \\
\hline Transitional Predictors & .168 & 15.36 & & & .000 \\
\hline $\begin{array}{l}\text { Relative Autonomy } \\
\text { Index }\end{array}$ & & & .122 & 0.02 & .076 \\
\hline $\begin{array}{l}\text { Acculturation } \\
\text { Motivation }\end{array}$ & & & .171 & 0.03 & .013 \\
\hline POPRS & & & .338 & 0.12 & .000 \\
\hline Proximal Predictors & .340 & 35.44 & & & .000 \\
\hline English & & & .104 & 0.01 & .097 \\
\hline Residence Status & & & .031 & 0.00 & .503 \\
\hline Social Provisions Scale & & & .301 & 0.15 & .000 \\
\hline SUM & & & .079 & 0.01 & .192 \\
\hline SPUSS & & & .490 & 0.27 & .000 \\
\hline
\end{tabular}

Note: $N=209, R=.802(p<.01)$, Adjusted $R^{2}=.601$, SACQ: Student Adaptation to College Questionnaire, POPRS: Perception of Parental Reciprocity Scale, SUM: Student University Match, SPUSS: Student Perception of University Support and Structure. 
of the variance in SACQ while controlling for all other predictors in the current and previous block $\left(s r^{2}=.12\right)$. Acculturation Motivation was a positive predictor of adjustment outcomes, with a small effect size $\left(s r^{2}=\right.$ .03). The last block entered contained the Proximal Predictors, and contributed significantly to the change in $R^{2}\left(\Delta R^{2}=.363, p<.001\right)$. This block included two significant predictors - Social Provisions Scale (SPS) and Student Perception of University Support and Structure (SPUSS). Social Provisions (SPS) was a positive predictor of student adjustment with a medium effect size, accounting for $15 \%$ of the variance in SACQ $\left(s r^{2}=.15\right)$. Finally, Perceived University Support and Structure (SPUSS) was related to better adjustment outcomes with a large effect size, accounting for $27 \%$ of the variance in SACQ while controlling for all other predictors in the current and previous blocks $\left(s r^{2}=.27\right)$.

The same analysis was also successfully conducted with the subscales of the SACQ, accounting for $57 \%$ of the variance in the Institutional Attachment subscale, $49 \%$ of Social Adjustment subscale, 42\% of the Academic Adjustment subscale, and 31\% of the Personal-Emotional Adjustment subscale (if interested, please contact the author for the full hierarchic regression results for the subscales).

\section{DISCUSSION}

The present study accomplished two major advances for research with international students. First, it demonstrates the utility of a theoretically based developmental sequential model in predicting international students' adjustment, accounting for over $60 \%$ of the variance in the adjustment scores. Second it introduces the SACQ (Baker \& Siryk, 1989) for assessing the adjustment of international students, with a Cronbach alpha of .93 in this international student sample, indicating strong internal consistency.

A hierarchical regression model consisting of variables relevant to a developmental-systems framework, arranged in developmental sequence, explained over sixty percent of the variance in SACQ mean scores. This developmental model for international students was an extension of the developmental sequential models used successfully by Wintre and Yaffe (2000), and Wintre and Bowers (2007) to examine adjustment and perseverance of domestic students. The results affirm the developmentalsystem perspective as a viable approach and provide valuable insight into the unique experiences of international students in a Canadian context. This model needs to be replicated at other American and Canadian universities and colleges.

\section{Distal predictors}

Demographic variables such as age, gender, family income and parental education, were not significant predictors of student adjustment, consistent 
with the non-significant demographic variables found by Wintre and Bowers (2007) in examining persistence to graduation in domestic students. Furthermore, high school GPA, included among the distal predictors in the first block, was not a significant predictor of adjustment. It is important to note that these findings are contrary to institutional assumptions in recruiting. In contrast, the regions of origin (see Table 1) contributed significantly to explaining a modest portion of the variance. Students from the Caribbean and Africa had better adjustment scores than those from China and the Middle East; and those from China had better adjustment than those from the Middle East. Even though the category "Other" for region of origin was also a positive significant predictor, its interpretation is impeded by its heterogeneity. This issue emphasizes the need for further research to examine countries of origin with greater sample sizes and improved discernibility.

The present results regarding country of origin point to the unique needs of each subgroup, and make apparent the importance of understanding the unique cultural, linguistic, and institutional challenges that exist for different groups of international students. For instance, Tidwell and Hanassab (2009) found that African and Asian international students were the two groups reporting the greatest number of needs. In their study, international students from Africa expressed the greatest concern for dealing with discrimination concerns, and Asian and East Asian international students for dealing with psychological issues (Tidwell \& Hanassab, 2009). Similar research has documented the heightened psychological needs of East Asian international students (Li, Wang, \& Xiao, 2014).

\section{Transitional Factors}

The Transitional Factors block contributed the second highest change in $R^{2}$ in the regression model. Within that block, Acculturation Motivation, in line with previous research by Chirkov et al., (2008) and Dentakos et al. (2016), was a modest positive predictor of international student adjustment, with a squared semi-partial correlation $\left(s r^{2}\right)$ of .03 , indicating it accounted for 3\% of the variance in SACQ adjustment scores after having controlled for other predictors present in the current and preceding block. This suggests that international students' willingness to go beyond mere academic concerns and engage with the host country, its culture, language and people, is likely to enhance a better transition and adjustment to university in comparison to students who approach their sojourn experience as essentially temporary with no interest in integration (Dentakos et al., 2016).

Perceived Reciprocity with Parents (POPRS) was also a significant predictor within the transitional block, with a large effect size $\left(s r^{2}=.13\right)$. This is noteworthy as it is the first study to investigate and establish the long 
term importance, even when away from home, of positive, age-appropriate relations with parents to international student adjustment. POPRS, which assesses the degree of perceived reciprocity in emerging adults' relationships with their parents, is based on Youniss's (1980) theory that relations with parents undergo a developmental transformation in later adolescence/ emerging adulthood toward greater mutual respect and symmetry (Wintre et al., 1995). In research on domestic Canadian students, POPRS has demonstrated strong levels of validity and reliability in emerging adults, and has been linked to adjustment in first year university student, and persistence to graduation (Wintre et al., 1995; Wintre, \& Yaffe, 2000). Furthermore, the degree to which a student's reciprocity score increased in the first year predicted the average rate of positive adaptation change across time (Wintre \& Dilouya, 2011). Finally, the findings by Chirkov et al. (2007; 2008) regarding self-determined motivation in international students' choice to study abroad being predictive of positive student outcomes were not replicated in the present study. It is possible that the different outcome measures used, in this case student adjustment to university as compared to psychological well-being measures (i.e. satisfaction with life), are not similarly related to the source of students' motivations. This also emphasizes the need for a more standardized measure of university adjustment to compare findings between studies.

The present study extends the continued importance of parents to university students' adjustment (Wintre \& Yaffe, 2001; Wintre \& Bowers, 2007) to international students and confirms the significance of international students' relationships with parents on adjustment throughout their undergraduate studies. Although this may run contrary to the stereotype of the international student as a sojourner in a foreign country and separated and disconnected from their home network, recent research on the communication pattern of current international students paints a different picture in that international students use a variety of communication media to stay in contact with their families - with phone calls, Skype, and e-mail being most frequently used (Chavoshi, Wintre, \& Wright., 2011). On average, international students communicate 2 to 3 times a week with their mothers and 1 to 2 times per week with their fathers (Chavoshi et al., 2011). More importantly, their communication frequency is positively associated with the perceived level of reciprocity with parents.

\section{Interaction with the Institution}

Over forty percent of the variance in the adjustment scores (constituting two-thirds of all variance explained by the regression model) is accounted for by two predictors: Social Provisions Scale and Student Perception of University's Support and Structure. Alongside the significance of the students' parental relationships, these measures point to the important 
role that ecological interactions play in the adjustment of international students over that of any fixed trait, characteristics, or attributes of the student proper. This is relevant to University recruitment procedures, which err on the emphasis of GPA, TOEFL and IEALT, and possibly underestimate the university environment and support services during the transition process.

Understanding the importance of these interactional and context based supports can be aided by our understanding of international students as emerging adults (Wintre et al., 2015). The period of instability characterizing emerging adulthood unfolds in conjunction to a rebalancing of the parental relationship where the emerging adult negotiates greater autonomy (Youniss \& Smollar, 1985; Arnett, 2006; 2012). With this increased independence from parents, emerging adults are permitted opportunities to explore multiple life directions in the fields of love, work, and world beliefs (Arnett, 2000). However, most emerging adults remain only semi-autonomous, continuing to rely on parents and institutions (e.g., university, military) to scaffold their prolonged entry into adulthood (Arnett, 2006; 2012). For international students, away from parents and family, the role institutions play in scaffolding their development is of particular significance. The fact that emerging adulthood is more normative in Western countries suggests that what international students are experiencing in Western schools may not be typical with regard to what their parents expect, or what peers back home are experiencing. This heightens the need for universities to be attuned to the adjustment needs of these emerging adults.

Social Support was a significant predictor accounting for a large share of the variance. This finding corroborates a number of previous studies showing the important role social support plays in the transition and adjustment of international students (Poyrazli, Kavanaugh, Baker \& AlTimimi, 2004; Ramsay et al., 2007; Yeh \& Inose, 2003). For example, Mallinckrodt and Leong (1992) found that the quality of the social support system had not only a direct, but also a buffering effect when international students were undergoing psychological stress. Nonetheless, Ramsay et al. (2007) found that international students expressed less social support compared to domestic students. Other researchers suggest that one of the biggest challenges faced by international students is a loss or lack of social support (Haves \& Lin, 1994; Pedersen, 1991). Consequently, an essential role of a university's international office must be to facilitate and encourage the development of international students' social networks.

Student Perception of University Support and Structure (SPUSS), entered in the last block in the regression models, was a positive predictor of adjustment scores and accounted for the greatest share of the variance $\left(s r^{2}=\right.$ .28). This measure is rooted in a systems theory perspective, focusing on the 
dynamic and ongoing interaction between the student and university rather than static traits of the individual (Wintre et al., 2008; Wintre et al., 2009).

The role of the relationship between the institution and adjustment of the international student is further highlighted by the relative large effect size of SPUSS in predicting positive student adaptation. High scores on SPUSS would represent students' perceptions of the university experience as supportive, structured and demanding (authoritative); as opposed to being over punitive and demanding (authoritarian) or one that is neither supportive nor demanding (permissive or neglectful). The overwhelming importance of the effect of ecological interaction on international students' adjustment, combined with the irrelevance of high school GPA and standardized English scores, demand a critical reappraisal of the current recruitment and admission process and a paradigm shift in how institutions view the transition and adjustment of international students. These results encourage us to examine and foster an environment and relationships in which the majority of students can thrive.

A potential limitation of the current study is the cross-sectional design. Although academic year was used as a control variable, ideally students should be followed throughout their four undergraduate years, giving more credence to the theorized temporal sequence and causal relationships found in the current study. A second limitation is with regard to sample size and country of origin. In the current study, due to sample size limitations, most countries of origin were grouped into geographic regions for analysis. To arrive at a more precise understanding of the unique needs and challenges faced by each national group, a larger sample that does not require such clustering is preferable. Finally, to capture the unique experience of international students, quantitative research projects such as the current study would benefit from the incorporation of qualitative data to assist in interpreting the findings (e.g., Dentakos et al, 2016).

\section{CONCLUSION AND IMPLICATIONS}

This is the first study to investigate international students' experiences from a developmental and theoretical framework that focuses on their role as students and emerging adults. The current study also makes a significant contribution in understanding the academic and applied issues pertinent to the increase of international students at North American universities and important to improving their experiences. Although, as with most studies, the present study has some limitations, these were partially addressed i.e., the cross sectional nature was addressed by using academic year as a control variable; and some limited sample sizes for countries of origin (data from 60 countries) were grouped according to geographic areas. The study's strengths include that it is theoretically based, a sample from a wide variety of 
different countries of origin, a large number of new and old potential predictor variables, and a developmental sequential model for university students which proved useful accounting for $60 \%$ of the variance. Furthermore, the variables identified as predictor variables are instructive not only for new criteria for accepting international students, but also in terms of developing university programs that address international students' needs.

The results should serve as a clarion call to universities to increase and revise student services and research on international student adjustment on par with increased recruitment and enrolment initiatives. Hopefully, these will jointly serve to supplant the myth of the ideal recruitment student candidate, defined as having a stellar high school GPA and TOEFL scores, with the empirically based understanding that when it comes to the adjustment of international students, the students' motivation to acculturate, experiences in the university, and the programs developed for international students, are of greater importance. From a research point of view, another advantage of the present study is that it introduces the SACQ, a widely employed and excellent psychometric measure for domestic students, as relevant for use with international student populations. Having an outcome variable that can be used with confidence by other researchers will also allow for informative comparisons between different research findings.

\section{REFERENCES}

Al-Sharideh, K. A., \& Goe, W. R. (1998). Ethnic communities within the university: An examination of factors influencing the personal adjustment of international students. Research in Higher Education, 39(6), pp. 699725 .

Arnett, J. J. (2000). Emerging adulthood: A theory of development from the late teens through the twenties. American Psychologist, 55(5), 469-480. doi:10.1037/0003-066X.55.5.469

Arnett, J. J. (2006). The psychology of emerging adulthood: What is known, and what remains to be known? In J. J. Arnett \& J. L. Tanner (Eds.), Emerging adults in America: Coming of age in the 21st century (pp. 303-330). Washington, DC: American Psychological Association.

Arnett, J.J. (2012). New horizons in emerging and young adulthood. In A. Booth, S.L. Brown, N.S. Landale, W.D. Manning, \& S.M. McHale (Eds.), Early adulthood in a family context (pp. 231-244). New York: Springer.

Baker, R. W., \& Siryk, B. (1984). Measuring adjustment to college. Journal of Counseling Psychology, 31(2), 179-179.

Baker, R. W., \& Siryk, B. (1989). Student adaption to college questionnaire (SACQ). Los Angeles, CA: Western Psychological Services.

Bevis, T.B. (2002). At a glance: International students in the United States. International Educator 11(4), 2-4. 
Beyers, W., \& Goossens, L. (2002). Concurrent and predictive validity of the student adaptation to college questionnaire in a sample of European freshman students. Educational and Psychological Measurement, 62(3), 527-527-538. doi:10.1177/00164402062003009

Beyers, W., \& Goossens, L. (2003). Psychological separation and adjustment to university: Moderating effects of gender, age, and perceived parenting style. Journal of Adolescent Research, 18(4), 363-382. doi: $10.1177 / 0743558403018004003$

Black, J. S., \& Mendenhall, M. (1990). The U-curve adjustment hypothesis revisited: A review and theoretical framework. Journal of International Business Studies, 22, 225-247.

Buote, V. M., Pancer, S. M., Pratt, M. W., Adams, G., Birnie-Lefcovitch, S., Polivy, J., \& Wintre, M. G. (2007). The importance of friends: Friendship and adjustment among 1st-year university students. Journal of Adolescent Research, 22(6), 665-689. doi:10.1177/0743558407306344

Canadian Bureau for International Education (2013). Flagship 2013: A World of Learning - Canada's Performance and Potential in International Education.

Chavoshi, S., Wintre, M.G., \& Wright, L. (2011, October). Does distance make the heart grow fonder? International students' communication and perceived reciprocity with parents. Paper presented at the 5th Conference on Emerging Adulthood, Providence, RI.

Chavoshi S., Wintre M.G., \& Wright L. (2012, June). International Students, English Competence, and the Adaptation to College Questionnaire. Paper presented at the Annual Meeting of the Canadian Psychological Association, Halifax, Nova Scotia, Canada.

Chirkov, V. I., Safdar, S., de Guzman, J., \& Playford, K. (2008). Further examining the role motivation to study abroad plays in the adaptation of international students in Canada. International Journal of Intercultural Relations, 32(5), 427-440. doi:10.1016/j.ijintrel.2007.12.001

Chirkov, V., Vansteenkiste, M., Tao, R., \& Lynch, M. (2007). The role of selfdetermined motivation and goals for study abroad in the adaptation of international students. International Journal of Intercultural Relations, 31(2), 199-222doi:10.1016/j.ijintrel.2006.03.002

Church, A. T. (1982). Sojourner adjustment. Psychological Bulletin, 91(3), 540540-572. doi:10.1037/0033-2909.91.3.540

Cohen, B. H. (2001). Explaining psychological statistics (2nd ed.). New York: Wiley.

Conti, R. (2000). College goals: Do self-determined and carefully considered goals predict intrinsic motivation, academic performance, and adjustment during the first semester? Social Psychology of Education, 4, 189-211.

Cook, R. D. (1977). Detection of influential observations in linear regression. Technometrics, 19, 15-18.

Cooper, S. E., \& Robinson, D. A. (1988). Psychometric properties of the student adaptation to college questionnaire with engineering and science students. Measurement and Evaluation in Counseling and Development, 21(3), 124129. 
Deci, E. L., \& Ryan, R. M. (1985). Intrinsic motivation and self-determination theory of human behavior. New York: Plenum.

Dentakos, S., Wintre, M., Chavoshi, S., \& Wright, L. (2016). Acculturation Motivation in International Student Adjustment and Permanent Residency Intentions: A Mixed-Methods Approach. Emerging Adulthood. doi: $10.1177 / 2167696816643628$

Eccles, S. J., Lord, E. S., \& Roeser, W. R. (1996). Round holes, square pegs, rocky roads, and sore feet: The impact of stage-environment fit in young adolescents' experiences in schools and families. In D. Cicchetti \& S. L. Toth (Eds.), Adolescence: Opportunities and the challenges (Vol. 7, pp. 47-92). Rochester, NY: University of Rochester Press.

Fass-Holmes, B., \& Vaughn, A. A. (2015). Evidence that international undergraduates can succeed academically despite struggling with English .Journal of International Students, 5(3), 228-243.

Feinstein, B. E. S., \& Ward, C. (1990). Loneliness and psychological adjustment of sojourners: New perspectives on culture shock. In D. M. Keats, D. Munro, \& L. Mann (Eds.), Heterogeneity in cross-cultural psychology. Lisse, Netherlands: Swets \& Zeitlinger.

Foreign Affairs, Trade and Development Canada. (2013). "Economic Impact of International Students in Canada". News Release - 2013. Retrieved from http://www.international.gc.ca/education/report-rapport/economic-impacteconomique/sec_4.aspx?lang=eng

Gebhard, J. G. (2012). International students' adjustment problems and behaviors. Journal of International Students,2 (2), 158-164 .

Gerdes, H., \& Mallinckrodt, B. (1994). Emotional, social, and academic adjustment of college students: A longitudinal study of retention. Journal of Counseling \& Development, 72(3), 281-288. doi:10.1002/j.15566676.1994.tb00935.x

Gold, J., Burrell, S., Haynes, C., \& Nardecchia, D. (1990). Student adaptation to college as a predictor of academic success: An exploratory study of Black undergraduate education students. Kent, OH: Kent State University. (ERIC Focument Reproduction Service No. ED331946)

Gong, Y. (2003). Goal orientations and cross-cultural adjustment: An exploratory study. International Journal of Intercultural Relations, 27(3), 297-305.

Gong, Y., \& Fan, J. (2006). Longitudinal examination of the role of goal orientation in cross-cultural adjustment. Journal of Applied Psychology, 91(1), 176184. doi:10.1037/0021-9010.91.1.176

Gullahorn, J. T., \& Gullahorn, J. E. (1963). An extension of the U-curve hypothesis. Journal of Social Issues, 19(3), 33-47.

Haves, L H., \& Lin, H. R. (1994). Coming to America: Developing social support systems for international students. Journal of Multicultural Counselling and Development, 22, 7-16.

Hechanova-Alampay, R., Beehr, T. A., Christiansen, N. D., \& Van Horn, Roger K. (2002). Adjustment and strain among domestic and international student sojourners: A longitudinal study. School Psychology International, 23(4), 458-474. doi:10.1177/0143034302234007.

Hertel, J. (2002). College student generational status: Similarities, differences, and factors in college adjustment. Psychological Record, 52, 3-18. 
Hinderlie, H. H., \& Kenny, M. (2002). Attachment, social support, and college adjustment among black students at predominantly white universities. Journal of College Student Development, 43(3), 327-340.

Hurtado, S., Carter, D. F., \& Spuler, A. (1996). Latino Student Transition to College: Assessing Difficulties and Factors in Successful College Adjustment. Research in Higher Education, 37(2), 135-157.

Institute of International Education. (2012). "International Student Enrollment Trends, 1949/50-2011/12". Open Doors Report on International Educational Exchange. Retrieved from http://www.iie.org/opendoors.

Johnson. D. C. (1971). Problems of foreign students. International Educational and Cultural Exchange, 7, 61-68.

Krotseng, M. V. (1992). Predicting persistence from the Student Adaptation to College Questionnaire: Early warning or siren song? Research in Higher Education, 33, 99-111.

Lee, J. J. (2008). Beyond borders: International student pathways to the US. Journal of Studies in International Education, 12, 308-27.

Lee, J. (2010). International students' experiences and attitudes at a US host institution: Self-reports and future recommendations. Journal of Research in International Education, 9(1), 66-84. doi:10.1177/1475240909356382

Lee, J., Koeske, G. F., \& Sales, E. (2004). Social support buffering of acculturative stress: A study of mental health symptoms among Korean international students. International Journal of Intercultural Relations, 28(5), 399-414. doi:10.1016/j.ijintrel.2004.08.005

Lerner, R.M. (2004). Diversity in individual $\leftarrow \rightarrow$ context relations as the basis for positive development across the life span: a developmental systems perspective for theory, research, and application. Research in Human Development, 1, 327-346.

Lysgaard, S. (1955). Adjustment in a foreign society: Norwegian Fulbright grantees visiting the United States. Acta Psychologica, 11, 189-190. doi:10.1016/S0001-6918(55)80082-0

Mallinckrodt, B., \& Leong, F. T. (1992). International graduate students, stress, and social support. Journal of College Student Development, 33(1), 71-78.

Matsumoto, D., LeRoux, J. A., Bernhard, R., \& Gray, H. (2004). Unraveling the psychological correlates of intercultural adjustment potential. International Journal of Intercultural Relations, 28(3-4), 281-309. doi:10.1016/j.ijintrel.2004.06.002

Mesidor, J. K., \& Sly, K. F. (2016). Factors that Contribute to the Adjustment of International Students. Journal of International Students 2016 Vol 6 Issue 1, 6(1), 262-282.

Mooney, S. P., Sherman, M. F., \& LoPresto, C. T. (1991). Academic locus of control, self-esteem, and perceived distance from home as predictors of college adjustment. Journal of Counseling and Development, 69, 445-448.

Murphy, M. C., \& Archer, J. (1996). Stressors on the college campus: A comparison of 1985-1993. Journal of College Student Development, 37(1), 20-28.

Norvilitis, J. M., Sun, L., \& Zhang, J. (2010). ADHD symptomatology and adjustment to college in china and the United States. Journal of Learning Disabilities, 43(1), 86-94. doi:10.1177/0022219409345012 
Pedersen, P. (1991). Counseling international students. The Counselling Psychologist, 19, 10 - 58.

Pimpa, N. (2003). The influence of peers and student recruitment agencies on Thai students' choices of international education. Higher Education, 7(2), 17892.

Poyrazli, S., Kavanaugh, P. R., Baker, A., \& Al-Timimi, N. (2004). Social support and demographic correlates of acculturative stress in international students. Journal of College Counseling, 7(1), 73-73-82.

Ramsay, S., Jones, E., \& Barker, M. (2007). Relationship between adjustment and support types: Youngand mature-aged local and international first year university students. Higher Education, 54(2), 247-265. doi:10.1007/s10734-006-9001-0

Rawlings, M., \& Sue, E. (2013). Preparedness of Chinese students for American culture and communicating in English. Journal of International Students, 3(1), 29-39.

Schwitzer, A. M., Robbins, S. B., \& McGovern, T. V. (1993). Influences of goal instability and social support on college adjustment. Journal of College Student Development, 34, 21-25.

Searle, W., \& Ward, C. (1990). The prediction of psychological and sociocultural adjustment during cross-cultural transitions. International Journal of Intercultural Relations, 14(4), 449-449-464. doi:10.1016/01471767(90)90030-Z

Stafford, T. H., Marion, R B., and Salter, M. L. (1980). Adjustment of international students. National Association of Student Personnel Administration 18, 4045.

Taft, R. (1977). Coping with unfamiliar culture. In Neil Warren (ed.), Studies in Cross-Culture Psychology vol. I (pp. 121-153). London: Academic Press.

Tao, S., Dong, Q., Pratt, M. W., Hunsberger, B., \& Pancer, S. M. (2000). Social support: Relations to coping and adjustment during the transition to university in the People's Republic of China. Journal of Adolescent Research, 15(1), 123-144. doi:10.1177/0743558400151007

Thomas, K., \& Harrell, T. (1994). Counseling student sojourners: Revisiting the Ucurve of adjustment. In G. Althen (Ed.). Leaning Across Cultures (pp. 89107). Washington. DC: NAFSA: Association of International Educators.

Tinto, V. (1996). Reconstructing the first year of college. Planning for Higher Education, 25, 1-6.

Toyokawa, T., \& Toyokawa, N. (2002). Extracurricular activities and adjustment of Asian international students: A study of Japanese students. International Journal of Intercultural Relations, 26(4), 363-363-379. doi:10.1016/S0147-1767(02)00010-X

Van Oudenhoven, J. P., \& Van der Zee, K. I. (2002). Predicting multicultural effectiveness of international students: The multicultural personality questionnaire. International Journal of Intercultural Relations, 26(6), 679694. doi:10.1016/S0147-1767(02)00041-X

Vaz, P. (1984). Stress, adjustment and social relations of foreign students. Ph.D. dissertation. University of Nebraska-Lincoln.

Verbik, L. and V. Lasanowski (2007) International Student Mobility: Patterns and Trends London: The Observatory on Borderless Higher Education. 
Wampold, B. E., \& Freund, R. D. (1987). Use of multiple regression in counseling psychology research: A flexible data-analytic strategy. Journal of Counseling Psychology, 34, 372-382.

Wang X. (2000). Develop and utilize the resources of Chinese students in the United States. Chinese Education and Society 33(5), 21-30.

Li, J., Wang, Y., \& Xiao, F. (2014). East Asian international students and psychological well-being: A systematic review. Journal of International Students, 4(4), 301.

Wintre, M. G., Gates, S. K. E., Pancer, W. M., Pratt, M. S., Polivy, J., BirnieLefcovitch, S., \& Adams, G. (2009). The student perception of university support and structure scale: Development and validation. Journal of Youth Studies, 12(3), 289-306. doi:10.1080/13676260902775085

Wintre, M. G., Kandasamy, A. R., Chavoshi, S., \& Wright, L. (2015). Are International Undergraduate Students Emerging Adults? Motivations for Studying Abroad. Emerging Adulthood, 3(4), 255-264. doi: 10.1177/2167696815571665

Wintre, M. G., Knoll, G. M., Pancer, S. M., Pratt, M. W., Polivy, J., BirnieLefcovitch, S., \& Adams, G. R. (2008). The transition to university: The student-university match (SUM) questionnaire. Journal of Adolescent Research, 23(6), 745-769. doi:10.1177/0743558408325972

Wintre, M. G., \& Bowers, C. D. (2007). Predictors of persistence to graduation: Extending a model and data on the transition to university model. Canadian Journal of Behavioural Science/Revue Canadienne Des Sciences Du Comportement, 39(3), 220-234. doi:10.1037/cjbs2007017

Wintre, M.G. \& Dilouya, B. (2011, October). A Longitudinal Examination of Parental Reciprocity and its Relation to University Adjustment. Paper presented at the Biennial Meeting of the Society for research on Emerging Adults, Providence, Rhode Island, U.S.A.

Wintre, M. G., \& Morgan, A. S. (2009). Transferring post-secondary schools: Student perceptions, rationales, and experiences. Journal of Adolescent Research, 24(6), 726-749. doi:10.1177/0743558409341081

Wintre, M. G., Yaffe, M., \& Crowley, J. (1995). Perception of parental reciprocity scale (POPRS): Development and validation with adolescents and young adults. Social Development, 4(2), 129-148. doi:10.1111/j.14679507.1995.tb00056.x

Wintre, M. G., \& Yaffe, M. (2000). First-year students' adjustment to university life as a function of relationships with parents. Journal of Adolescent Research, 15(1), 9-37. doi:10.1177/0743558400151002

Yeh, C. J., \& Inose, M. (2003). International students' reported English fluency, social support satisfaction, and social connectedness as predictors of acculturative stress. Counselling Psychology Quarterly, 16(1), 15-15-28. doi:10.1080/0951507031000114058

Youniss, J., \& Smollar, J. (1985). Adolescent relations with mothers, fathers, and friends. Chicago: University of Chicago Press.

Zhang, J., \& Goodson, P. (2011). Predictors of international students' psychosocial adjustment to life in the United States: A systematic review. International Journal of Intercultural Relations, 35(2), 139-162. doi:http://dx.doi.org/10.1016/j.ijintrel.2010.11.011 
Zhou, S. J., \& Scratchley, T. (2005). Satisfaction as a factor influencing retention rates of international students at SFU. M.B.A., Simon Fraser University.

SAEID CHAVOSHI, is a doctoral student in Clinical-Developmental Psychology at York University. His research interests include the transition to university experience, time-management skills, and self-regulation.Email: chavoshi@yorku.ca

MAXINE G. WINTRE, Ph.D. , C. Psych. Department of Psychology at York University. Dr. Wintre is a Professor in the Clinical-Developmental Psychology area and her research interests have focused on relations with parents, emerging adulthood, and the transition to university. Email: mwintre@yorku.ca

STELLA DENTAKOS, is a doctoral student in Clinical-Developmental Psychology at York University. Her research interests include acculturation, cognitive effort, and temporal discounting. dentakos@yorku.ca

LORNA WRIGHT. Dr. Lorna Wright is EDC Professor of International Business, Associate Professor of Organizational Behaviour and Executive Director of the Centre for Global Enterprise at the Schulich School of Business, York University. Previously, she was Associate Vice President International of York University. Her $\mathrm{PhD}$ is from The University of Western Ontario and her research interests are in the areas of international students, cross-cultural management, and conditions for SME success internationally. Email: lwright@schulich.yorku.ca 